\title{
Teoria do adimplemento substancial e sua aplicabilidade pela Corte Goiana entre os anos de 2016 e 2019 na perspectiva comparatista
}

\author{
Theory of substantial performance and its applicability through \\ the Court Goiana Between the years of 2016 and 2019 in the \\ comparative perspective
}

\section{Felipe Aquino Domiciano}

Universidade Federal de Goiás

RESUMO A teoria do adimplemento substancial possui previsão doutrinária e jurisprudencial, podendo ser conceituada como empecilho à resolução contratual nas hipóteses em que há ínfimo descumprimento da obrigação pactuada entre os contratantes. Para aplicação da teoria é necessário o preenchimento de três requisitos. O objetivo do presente artigo é analisar um de seus requisitos, qual seja, o inadimplemento ínfimo, sob a perspectiva comparatista entre o Tribunal de Justiça do Estado de Goiás - TJGO e os principais tribunais do país. Por meio de pesquisa documental e bibliográfica, foram analisados 371 acórdãos proferidos pelo TJGO entre os anos de 2016 e 2019 sobre a temática, dos quais 247 se enquadraram nos critérios de inclusão e fizeram parte integrante dos resultados do presente artigo. Os resultados revelam que o TJGO aplica a referida teoria quando há um adimplemento mínimo de $80 \%$ da obrigação pactuada, ao comparar com os principais tribunais do país é possível verificar uma variação de $14 \%$, o que pode acarretar em disparidade de decisões e insegurança jurídica acerca da aplicabilidade da teoria. Como conclusão, é sugerido que o STJ intervenha e estabeleça um percentual que possa ser seguido pelos tribunais em tempos de pandemia da Covid-19.

Palavras-chave: Teoria do adimplemento substancial; Percentual; Goiás; TJGO; Covid-19.

ABSTRACT The theory of substantial performance has doctrinal and jurisprudential provision, and the contractual resolution can be conceptualized as an obstacle in the cases in which there is a minimal breach of the obligation agreed between the contractors. To apply the theory, it is necessary to fulfill three requirements. The purpose of this article is to analyze one of its requirements, namely, the smallest default, from a comparative perspective between the Goiás State Court of Justice - TJGO and the country's main courts. Through documentary and bibliographic research, 371 judgments handed down by the TJGO betwe- 
en the years 2016 and 2019 on the subject were analyzed, of which 247 met the inclusion criteria and formed an integral part of the results of this article. The results reveal that the TJGO applies this theory when there is a minimum performance of $80 \%$ of the agreed obligation, when comparing with the main courts in the country it is possible to verify a variation of $14 \%$, which can lead to disparity in decisions and legal uncertainty. about applicability theory. As a conclusion, it is suggested that the STJ intervene and establish a percentage that can be followed by the courts in times of Covid-19 pandemic.

Keywords: Theory of Substantial Performance; Percentage; Goiás; TJGO; CoVID-19.

\section{INTRODUÇÃo}

A teoria do adimplemento substancial pode ser conceituada como um obstáculo à faculdade do credor em resolver o vínculo contratual em face de uma mora insignificante, referente às obrigações totais pactuadas, o que permite uma percepção contratual mais justa, efetiva e garante à finalidade contratual (TARTUCE, 2019, p. 366-367).

$\mathrm{Na}$ perspectiva histórica, a teoria do adimplemento substancial foi originada na Inglaterra durante o século XVIII, com o objetivo de transpor excessos formais durante a execução contratual em casos de inadimplemento ínfimo da obrigação pactuada entre as partes (MOURA, 2020).

Para Pinto (2020), o adimplemento substancial é caracterizado quando há um descumprimento contratual próximo ao fim, retirando de cogitação a possibilidade de desfazimento do contrato, visando a sua manutenção, autorizando, apenas, o pedido de indenização.

No aspecto prático, em vez de resolver o contrato, a teoria impõe a preservação e possibilita a adoção de medidas menos gravosas para a recuperação do saldo devedor remanescente, por exemplo, a propositura de Ação de Cobrança ou Ação de Execução (PAULA, 2010, p. 43-67).

Para aplicabilidade da referida teoria, o Superior Tribunal de Justiça - STJ, por meio do Recurso Especial n ${ }^{\circ}$ 76.362/MT, de relatoria do Ministro Ruy Rosado de Aguiar, definiu três requisitos cumulativos, quais sejam: a) pagamento faltante há de ser ínfimo se considerado o valor total do contrato; b) existência de expectativas legítimas geradas pelo comportamento das partes; c) deve ser possível a conservação da eficácia do negócio sem prejuízo ao direito do credor em pleitear a quantia devida pelos meios ordinários (STJ, 1995).

Contudo, acerca do valor ínfimo, não há um parâmetro quantitativo fixo, sendo considerado como cláusula aberta e passível de interpretação por cada tribunal da unidade federativa do Brasil, o que pode acarretar em disparidade nas decisões judiciais proferidas em contextos fáticos semelhantes.

Nesse sentido, o presente artigo se propõe a analisar o "valor ínfimo faltante" da teoria do adimplemento substancial sob a ótica do Tribunal de Justiça do Estado de Goiás - TJGO, por meio do estudo de 371 acórdãos proferidos sobre a temática entre os anos de 2016 e 2019, os instrumentos processuais utilizados pelos advogados para debater a presente teoria no tribunal, os percentuais de acolhimento da teoria pelo tribunal, análise específica de cada câmara cível sobre a temática e o percentual aceito para aplicação da teoria. 
Tais demonstrações serão possíveis por meio das respostas dos seguintes questionamentos: a) qual o percentual mínimo adotado pelo Tribunal de Justiça do Estado de Goiás (TJGO) para a aplicação da teoria do adimplemento substancial? B) Com relação ao percentual adotado, há consenso entre os principais tribunais das unidades federativas brasileiras? C) Qual o principal instrumento para debater a referida teoria perante o tribunal?

Como hipótese, trabalha-se com a ideia de que o valor ínfimo faltante, na visão do TJGO, seja caracterizado quando houver o adimplemento substancial de, pelo menos, $80 \%$ (oitenta por cento) do contrato, tendo em vista que trata-se de um tribunal conservador por não possuir uma quantidade de julgados expressivos referentes à teoria em discussão; que não há consenso entre os tribunais acerca do percentual adotado pelo tribunal do Estado de Goiás; e o principal instrumento utilizado seja o recurso de apelação.

A importância desse tema ganha contornos concretos diante da atual pandemia da Covid-19 que revela a fragilidade dos contratos diante de uma economia assolada. O fator determinante para a escolha da teoria do adimplemento substancial é que a disparidade de decisões proferidas entre o TJGO e os principais tribunais da unidade federativa do Brasil pode culminar em uma prestação da tutela jurisdicional desprovida de equilíbrio.

Assim, utilizou-se vasta pesquisa documental caracterizada pela análise de 371 acórdãos proferidos pelo TJGO, bibliográficas representadas pelas doutrinas colacionadas, artigos, leis e jurisprudências sobre o tema. Ainda, foram analisados os bancos de jurisprudências dos principais tribunais do país com escopo de comparar o percentual aceito para aplicabilidade da referida teoria.

Destarte, a partir deste estudo será proporcionado o entendimento acerca da aplicabilidade da teoria do adimplemento substancial pelo TJGO no que tange o percentual aceito para aplicação, a visão de cada câmara cível do tribunal e, ainda, uma perspectiva comparada com os principais tribunais do país.

\section{A TEORIA DO ADIMPLEMENTO SUBSTANCIAL NA ÓTICA DOUTRINÁRIA}

Por não possuir previsão específica no ordenamento jurídico brasileiro, a teoria do adimplemento substancial foi reformulada com base nos princípios da boa-fé objetiva, função social dos contratos, vedação do enriquecimento ilícito e do abuso de direito, conforme preceitua o enunciado 361 da IV Jornada de Direito Civil (CJF, 2016).

O Art. 475 do Código Civil expressa que "a parte lesada pelo inadimplemento pode pedir a resolução do contrato, se não preferir exigir-lhe o cumprimento, cabendo, em qualquer dos casos, indenização por perdas e danos" (BRASIL, 2002).

Anelise Becker (1993, p. 60-77), apresenta uma visão acerca da responsabilidade civil da teoria e esclarece que "o adimplemento substancial consiste em um resultado tão próximo do almejado, que não chega a abalar a reciprocidade, o sinalagma das prestações correspectivas" e ressalta que se houver defeitos da prestação, ainda que secundário, existirá o dever de reparação civil.

Cristiano Chaves e Nelson Rosenvald (2016, p. 200), esclarecem que o inadimplemento mínimo impede que o credor adote o remédio resolutório, porém não impede a adoção de outras ações permitidas em lei que são consideradas menos gravosas ao devedor 
que já pagou um valor considerável do contrato pactuado.

Para aplicação da teoria do adimplemento substancial no caso concreto, o Superior Tribunal de Justiça - STJ (2016), adota o seguinte entendimento:

DIREITO CIVIL. RECURSO ESPECIAL. RESCISÃO CONTRATUAL. REINTEGRAÇÃO NA POSSE. INDENIZAÇÃO. CUMPRIMENTO PARCIAL DO CONTRATO. INADIMPLEMENTO. RELEVÂNCIA. TEORIA DO ADIMPLEMENTO SUBSTANCIAL. INAPLICABILIDADE NA ESPÉCIE. RECURSO NÃO PROVIDO. 1. O uso do instituto da substancial performance não pode ser estimulado a ponto de inverter a ordem lógico-jurídica que assenta o integral e regular cumprimento do contrato como meio esperado de extinção das obrigações. 2. Ressalvada a hipótese de evidente relevância do descumprimento contratual, o julgamento sobre a aplicação da chamada "Teoria do Adimplemento Substancial" não se prende ao exclusivo exame do critério quantitativo, devendo ser considerados outros elementos que envolvem a contratação, em exame qualitativo que, ademais, não pode descurar dos interesses do credor, sob pena de afetar o equilíbrio contratual e inviabilizar a manutenção do negócio. 3. A aplicação da Teoria do Adimplemento Substancial exigiria, para a hipótese, o preenchimento dos seguintes requisitos: a) a existência de expectativas legítimas geradas pelo comportamento das partes; b) o pagamento faltante há de ser ínfimo em se considerando o total do negócio; c) deve ser possível a conservação da eficácia do negócio sem prejuízo ao direito do credor de pleitear a quantia devida pelos meios ordinários (critérios adotados no REsp 76.362/MT, QUARTA TURMA, j. Em 11/12/1995, DJ 01/04/1996, p. 9917) [...]. (REsp n ${ }^{\circ} 1.581 .505$ / SC, Relator: Ministro Antonio Carlos Ferreira, Órgão Julgador: $4^{a}$ turma, julgamento: 18/08/2016, publicação: DJe 28/09/2016).

O presente julgado destaca duas considerações importantes: a) a teoria do adimplemento substancial é de aplicabilidade excepcional e não pode inverter a ordem lógico-jurídica de modo a incentivar que o devedor deixe de cumprir a integralidade do contrato celebrado e interrompa sua extinção natural; e b) ressalta requisitos que norteiam uma aplicação justa da teoria.

Tais requisitos podem ser caracterizados como critérios qualitativos e quantitativos. Os critérios qualitativos advêm da qualidade das partes, quais sejam o credor e o devedor, que devem demonstrar a existência de expectativas legítimas e de meios ordinários para a cobrança da dívida. Já o critério quantitativo advém da quantidade, ou seja, o valor devido deve ser ínfimo se considerado ao total do negócio (ARAÚJO, 2017).

Junior e Rodas (2015, pág. 335) destaca que Reinhard Zimmermann e Jan Peter Schimidt seguem o posicionamento do STJ e que a liberdade contratual está intrinsicamente ligada a responsabilidade dos atos consequentes do contrato celebrado:

[a] liberdade contratual implica autodeterminação e responsabilidade pelos próprios atos. As partes que celebram um contrato devem arcar com as consequências que isso possa acarretar, desde que não tenham sido ludibriadas ou enganadas de alguma forma, nem tenham sido coagidas. [...] O Direito dos Contratos e a liberdade contratual não são fins em si mesmos. São meios para permitir às partes exercer seu direito de autodeterminação. Evidentemente, um contrato deve ser o resultado de um ato de autodeterminação de ambas as partes. E o 
Direito precisa garantir que ambas as partes de fato possam tomar uma decisão autodeterminada. (Entrevista com Reinhard Zimmermann e Jan Peter Schmidt. Disponível em: $<$ http://ojs.direitocivilcontemporaneo.com/index.php/rdcc/ar$\underline{\text { ticle/view/79> }}$. Acesso em 30 nov. 2021).

Segundo Eduardo Luiz Bussatta (2008), o juiz deve valorar a gravidade do inadimplemento com base em todas as circunstâncias apresentadas no caso concreto, partindo de um juízo de aproximação entre o programa contratual e o conteúdo da prestação realizada pelo devedor, sobretudo a turbação ao equilíbrio do contrato celebrado, sua natureza, o comportamento das partes etc.

Com a edição da Medida Provisória $n^{\circ}$ 881/2019, conhecida como MP da Liberdade Econômica e, posteriormente, convertida na Lei 13.874/19, houve uma importante alteração no modo de compreender a teoria do adimplemento substancial a depender do caso concreto e nível de conservação de cada tribunal (BRASIL, 2019), a saber:

A nova redação do artigo 421, parágrafo único do Código Civil, aduz que "nas relações contratuais privadas, prevalecerão o princípio da intervenção mínima e a excepcionalidade da revisão contratual" (BRASIL, 2019).

A primeira possível corrente é que, ao prever expressamente a teoria da intervenção mínima no Código Civil, houve uma limitação no poder de atuação do magistrado no momento da aplicação da teoria do adimplemento substancial, de modo a obrigá-lo a elevar o percentual mínimo para garantir uma intervenção mínima nas demandas que buscam a sua aplicação.

Uma segunda possível corrente, por meio da expressa previsão da teoria da intervenção mínima, o magistrado pode valer-se da teoria e garantir a aplicação da teoria do adimplemento substancial por intermédio da redução do percentual referente ao valor ínfimo e optar pela manutenção do contrato, já que a legislação já garante ao credor ferramentas judiciais para se chegar à quitação do débito, o que pode garantir uma intervenção mínima nas relações contratuais.

O STJ (2017), por meio do REsp n ${ }^{\circ} 1.622 .555 / \mathrm{MG}$, limitou o campo de aplicabilidade da teoria do adimplemento substancial ao estabelecer que a teoria não é aplicável em contratos de alienação fiduciária em garantia em virtude do conflito de especialidade entre as normas.

Por fim, Venosa e Densa (2020), afirmam que a pandemia é uma situação de força maior, não tendo o que falar em culpa pelo inadimplemento em casos relacionados à pandemia, mas, em visão conservadora, os autores ressaltam a necessidade de se analisar o nexo de causalidade entre o inadimplemento e a pandemia em cada caso concreto. Se houver nexo de causalidade, as consequências do inadimplemento, como inserir o devedor nos cadastros de inadimplentes, protestar o título, requerer o vencimento antecipado das prestações, resolução contratual (exceto em casos de onerosidade excessiva), dentre outros, não poderão ser exercidos.

\section{Metodologia}

Para a realização do artigo foi empregada a pesquisa documental (caracterizada pelos acórdãos analisados) e bibliográfica (caracterizada pelas doutrinas, artigos e estudos jurídicos que abrangiam o tema em análise). 
Os critérios de inclusão foram: a) o recurso que levou a matéria ao tribunal devem ser apelação, agravo de instrumento ou ação autônoma de Habeas Corpus; b) acórdãos julgados entre o período de 01 de janeiro de 2016 e 30 de setembro de 2019; c) abordar a teoria do adimplemento substancial, d) acórdão proferido pelo TJGO.

Os critérios de exclusão foram: a) acórdãos que discutiam a teoria em sede de embargos de declaração; b) acórdãos proferidos pela seção cível; e c) acórdãos proferidos em Ação Rescisória, recursos administrativos e reexame necessário.

No sítio do TJGO, clicou-se na aba "atos judiciais/jurisprudências", posteriormente na barra lateral esquerda clicou-se na opção "jurisprudência" e abriu automaticamente uma caixa de busca, na qual foi inserido no espaço "texto para pesquisa" o termo "adimplemento substancial".

Foram reportados 371 acórdãos. Desse total, 77 acórdãos foram excluídos por não se enquadrarem no período de inclusão, restando 294 acórdãos. Por meio dos critérios de exclusão, dos 294 acórdãos incluídos na pesquisa, restaram 247 jurisprudências.

No que tange os acórdãos, todos foram proferidos pelas câmaras cíveis do TJGO, quais sejam $1^{\mathrm{a}}$ a $6^{\mathrm{a}}$, e a publicação ocorreu pelo site oficial do tribunal (www.tjgo.jus.br).

Os acórdãos dos Tribunais dos Estados de São Paulo, Minas Gerais, Paraná, Rio Grande do Sul, Distrito Federal, Mato Grosso, Bahia, Ceará, Pernambuco, Tocantins e Amazonas foram buscados na aba "jurisprudência" dos respectivos tribunais, posteriormente no campo de pesquisa livre foram inseridos os termos "adimplemento substancial aplicabilidade".

Os dados coletados foram digitados em planilhas da Microsoft Excel 2019 ${ }^{\circledR}$, nas quais foram aplicados procedimentos de estatística descritiva e os resultados ilustrados em tabelas com média, mediana, frequências absolutas e relativas.

\section{TeOria do adimplemento SUbSTANCial na ÓTICA do Tribunal de Jus- TIÇA dO ESTADO DE GOIÁs - TJGO}

\subsection{Aplicabilidade da teoria}

Foram analisados 247 acórdãos, proferidos entre 2016 e 2019, conforme tabela 1.

Tabela 1. Números de acórdãos analisados pelo TJGO sobre a teoria do adimplemento substancial entre os anos de 2016 e 2019.

\begin{tabular}{c|c|c}
\hline Decisão & $\mathbf{N}$ & $\mathbf{\%}$ \\
\hline Acolhido & 26 & 10,53 \\
\hline Não acolhido & 221 & 89,47 \\
\hline Total & $\mathbf{2 4 7}$ & $\mathbf{1 0 0 , 0 0}$ \\
\hline
\end{tabular}

Fonte: Banco de dados do autor.

Legenda: n: frequência absoluta; \%: frequência relativa. 
As principais justificativas utilizadas para a não aplicação da teoria do adimplemento substancial pelo TJGO são:

a) Não aplicação em casos que versam sobre contratos de alienação fiduciária em garantia, com base no Recurso Especial n $1.622 .555 / \mathrm{MG}$ :

É pacífico o entendimento no tribunal sobre a inaplicabilidade da teoria do adimplemento substancial em contratos de alienação fiduciária em garantia submetidos ao Decreto-Lei n. 911/69, em decorrência do conflito da especialidade, pois a doutrina é unânime ao entender que o Código Civil é uma norma geral e o Decreto-Lei n. 911/69 norma especial, razão pela qual em casos de atrasos no pagamento do financiamento é perfeitamente cabível a medida de busca e apreensão do bem em discussão previstos no Decreto-Lei n. 911/69 (BRASIL, 1969; BRASIL, 2002).

Contudo, antes do julgamento do Recurso Especial $\mathrm{n}^{\circ} 1.622 .555 / \mathrm{MG}$, realizado pelo STJ, a teoria do adimplemento substancial era perfeitamente aplicável aos contratos de alienação fiduciária em garantia regidos pelo Decreto-Lei n. 911/69, sendo que, dos 26 (vinte e seis) acórdãos que acolheram a aplicação da referida teoria, 11 (onze) acórdãos versaram sobre contratos de alienação fiduciária em garantia e foram favoráveis a aplicação da teoria em comento, todos julgados entre os anos de 2016 e 2017 (BRASIL, 1969; STJ, 2017).

Posterior ao Recurso Especial $\mathrm{n}^{\circ} 1.622 .555 / \mathrm{MG}$ do STJ, é perceptível por intermédio das Apelações Cíveis do TJGO n ${ }^{\text {os }}$ 0143931-48.2001.8.09.0051, 015480673.2016.8.09.0044 e 0112952-30.2006.8.09.0051 a inaplicabilidade da referida teoria nos casos em que há conversão da Ação de Busca e Apreensão para Ação de Depósito, tendo como origem contratos de alienação fiduciária (STJ, 2017; TJGO, 2019).

Por outro lado, o TJGO entendeu por meio da Apelação Cível n 005694049.2013.8.09.0051 ser cabível a aplicação da teoria do adimplemento substancial em hipóteses de celebração de contratos de arrendamento mercantil (leasing). Em suma, foi celebrado um contrato e houve um adimplemento substancial de 88,3\%, do contrato (TJGO, 2018).

b) Demora no prazo de entrega de imóveis edilícios e/ou rede básica, como energia, água e luz:

Em outra análise, verificou-se que a teoria do adimplemento substancial é constantemente suscitada em contratos de construtoras que, por motivos diversos, não iniciam ou não concluem os serviços pactuados em sede contratual. As consequências de tal omissão são perceptíveis na ausência de condições mínimas de habitação por parte do adquirente/ comprador, quer seja ausência de rede elétrica, saneamento básico, etc.

Nas Apelações Cíveis n 0060594-42.2015.8.09.0029 e 0218151-58.2016.8.09.0029, o TJGO consagrou o entendimento de que não é possível a aplicação da teoria do adimplemento substancial para atrasos superiores a um ano (TJGO, 2019).

c) Quando o valor faltante é inferior a $80 \%$ do contrato celebrado:

A presente discussão ocorrerá especificadamente no tópico 4.4 do presente artigo.

\subsection{Espécies recursais utilizadas}

O recurso de apelação foi a espécie mais utilizada para debater a teoria do adimplemento substancial, conforme tabela 2. 
Tabela 2. Espécies recursais e ação autônoma que abordaram a teoria do adimplemento substancial no TJGO entre os anos de 2016-2019.

\begin{tabular}{ccc}
\hline Recurso/Ação & $\mathbf{N}$ & $\mathbf{\%}$ \\
\hline Apelação & 135 & 54,66 \\
Agravo de Instrumento & 111 & 44,94 \\
Habeas Corpus & 1 & 0,40 \\
\hline Total & $\mathbf{2 4 7}$ & $\mathbf{1 0 0 , 0 0}$ \\
\hline
\end{tabular}

Fonte: Banco de dados do autor.

Utilizando o Habeas Corpus $n^{\circ}$ 158182-12.2019.8.09.0000, o tribunal consagrou a inaplicabilidade da teoria do adimplemento substancial em ações que se discutem os valores de dívidas oriundas de vínculos jurídicos familiares, por exemplo, demandas que versam sobre obrigações alimentares (TJGO, 2019).

Assim, o TJGO (2019) definiu o entendimento de que o Habeas Corpus é uma via inadequada para debater a matéria, tendo em vista que a gama de cobertura do Habeas Corpus não engloba a possibilidade de discussão acerca da aplicabilidade ou não da teoria do adimplemento substancial.

\subsection{Aplicabilidade por ano e por câmara cível}

Ao analisar o número geral dos acórdãos, é possível verificar que as $3^{\mathrm{a}}$ e $4^{\mathrm{a}}$ Câmaras Cíveis do TJGO foram as que mais apreciaram a teoria do adimplemento substancial, conforme tabela 3 .

Tabela 3. Número de acórdãos proferidos sobre a teoria do adimplemento substancial pelas câmaras cíveis do TJGO entre os anos de 2016 e 2019.

\begin{tabular}{ccccccc}
\hline Decisão & $\mathbf{1}^{\mathbf{a}}$ Câmara & $\mathbf{2}^{\mathbf{a}}$ Câmara & $\mathbf{3}^{\text {a }}$ Câmara & $\mathbf{4}^{\mathbf{a}}$ Câmara & $\mathbf{5}^{\mathbf{a}}$ Câmara & $\mathbf{6}^{\mathbf{a}}$ Câmara \\
\hline Acolhido & 5 & 6 & 7 & 4 & 2 & 2 \\
Não acolhido & 36 & 40 & 41 & 44 & 37 & 23 \\
\hline Total & $\mathbf{4 1}$ & $\mathbf{4 6}$ & $\mathbf{4 8}$ & $\mathbf{4 8}$ & $\mathbf{3 9}$ & $\mathbf{2 5}$ \\
\hline
\end{tabular}

Fonte: Banco de dados do autor.

Em análise detalhada, ficou constatado que a $3^{\text {a }}$ Câmara Cível foi a que mais aplicou a teoria com total de 7 (sete) acórdãos acolhidos, por vez, as $5^{\mathrm{a}}$ e $6^{\mathrm{a}}$ Câmaras Cíveis foram as que menos acolheram, com total de 2 (dois) acórdãos cada.

Quanto a análise da aplicação da teoria do inadimplemento substancial entre os anos de 2016 e 2019, verificou-se que no ano de 2016 ocorreu a maior incidência de aplicação, seguido pelo ano de 2017, conforme tabela 4 . 
Tabela 4. Índice de acórdãos que acolheram a teoria do adimplemento substancial no TJGO entre 2016 e 2019

\begin{tabular}{lllll}
\hline Decisão & $\mathbf{2 0 1 6}$ & $\mathbf{2 0 1 7}$ & $\mathbf{2 0 1 8}$ & $\mathbf{2 0 1 9}$ \\
\hline Acolhido & 16 & 5 & 3 & 2 \\
Não acolhido & 23 & 69 & 69 & 60 \\
\hline Total & $\mathbf{3 9}$ & $\mathbf{7 4}$ & $\mathbf{7 2}$ & $\mathbf{6 2}$ \\
\hline
\end{tabular}

Fonte: Banco de dados do autor.

Uma das justificativas que podem ser utilizadas para o alto índice de aplicação da referida teoria é que, em 2016, o STJ não havia se manifestado acerca da aplicabilidade ou não da referida teoria nos contratos de alienação fiduciária em garantia.

Sobre o assunto, o STJ manifestou apenas em 16 de março de 2017 por meio do Recurso Especial $\mathrm{n}^{\circ} 1.622 .555 / \mathrm{MG}$, no qual ficou decidido pela não incidência da referida teoria em contratos de alienação fiduciária em garantia (STJ, 2017), o que pode justificar, também, o baixo índice de aplicação nos anos seguintes em virtude da delimitação da aplicabilidade da teoria.

\subsection{Percentual aceito pelo TJGO}

A média do percentual aceito para a aplicação da teoria do adimplemento substancial, por intermédio da análise dos 26 acórdãos que admitiram a sua aplicabilidade é de $86,62 \%$, conforme tabela 5 .

Tabela 5. Percentual de aplicação da teoria do inadimplemento substancial pelo TJGO entre os anos de 2016 e 2019

\begin{tabular}{c|c}
\hline Espécie & $\%$ \\
\hline Mínimo & 70.00 \\
\hline $1^{\circ}$ Quartil & 80.00 \\
\hline Mediana & 87,50 \\
\hline Média & 86,62 \\
\hline $3^{\circ}$ Quartil & 90.00 \\
\hline Máximo & $\mathbf{1 0 0 . 0 0}$ \\
\hline
\end{tabular}

Fonte: Banco de dados do autor.

Legenda: \%: frequência relativa.

Apesar do valor médio encontrado, o TJGO possui o entendimento predominante, por meio do agravo de instrumento $\mathrm{n}^{\circ}$ 349652-62.2015.8.09.0000 e apelação cível $\mathrm{n}^{\circ}$ 18495621.2013.8.09.0051 que o valor ínfimo é caracterizado quando há o cumprimento mínimo de $80 \%$ da obrigação pactuada.

Todavia, existem acórdãos do próprio tribunal que acolheram o pedido de aplicação da teoria do adimplemento substancial em percentuais abaixo da média: 
a) A apelação cível Apelação Cível n 0411710-09.2013.8.09.0021 retrata a aplicabilidade da referida teoria com adimplemento contratual em $68,75 \%$ da obrigação pactuada (TJGO, 2019).

b) O agravo de instrumento $n^{\circ}$ 160555-09.2016.8.09.0000 retrata a aplicação da referida teoria no percentual de adimplemento contratual em 70\% (TJGO, 2016).

c) $\mathrm{Na}$ apelação cível $\mathrm{n}^{\circ}$ 0257042-53.2014.8.09.0051, o percentual acolhido foi de $70,83 \%$ (TJGO, 2018).

d) Já no agravo de instrumento $n^{\circ} 330855-38.2015 .8 .09 .0000$, o percentual acolhido foi de $75 \%$, portanto, mais próximo do entendimento consagrado pelo próprio tribunal (TJGO, 2016).

Por outro lado, o percentual mais alto analisado foi de $97,25 \%$, por intermédio da apelação cível $\mathrm{n}^{\circ}$ 0402885-09.2013.8.09.0011 que debateu sobre a aplicabilidade da teoria em um contrato de compromisso de compra e venda de imóvel no valor de R\$78.000,00 (setenta e oito mil reais) tendo como saldo devedor a quantia de $\mathrm{R} \$ 2.145,00$ (dois mil cento e quarenta e cinco reais), o que correspondia há $2,75 \%$ do contrato, sendo o tribunal favorável a aplicação da referida teoria (TJGO, 2017).

\subsection{Comparação do percentual entre o TJGO e os principais tribunais de justiça do país}

Conforme demonstrando no tópico 4.4, o TJGO possui o entendimento acerca da aplicabilidade da teoria do adimplemento contratual quando há um adimplemento substancial de, no mínimo, 80\% das obrigações pactuadas.

No entanto, ao analisar a média dos percentuais aceitos pelo tribunal, o percentual é elevado para $86,62 \%$ das obrigações.

Em contrapartida, os principais tribunais do país entendem que a aplicação da teoria do adimplemento substancial é condicionada ao percentual médio de 73,64\%, conforme tabela 06.

Tabela 6. Percentual de aplicação da teoria do adimplemento substancial pelos principais tribunais do país

\begin{tabular}{cc}
\hline Tribunal de Justiça & $\mathbf{\%}$ \\
\hline São Paulo & 70 \\
Minas Gerais & 70 \\
Paraná & 84 \\
Rio Grande do Sul & 72 \\
Distrito Federal & 75 \\
Mato Grosso & 80 \\
Bahia & 77 \\
Ceará & 70 \\
Pernambuco & 70 \\
Tocantins & 70 \\
Amazonas & 72 \\
\hline Média & $\mathbf{7 3 , 6 4}$ \\
\hline
\end{tabular}

Fonte: Banco de dados do autor.

Legenda: \%: frequência relativa. 
O Tribunal de Justiça do Estado do Paraná - TJPR (2019), por intermédio da apelação cível $n^{\circ}$ 0015099-25.2016.8.16.0035, entendeu que o percentual mínimo para aplicação da teoria do adimplemento substancial é $84 \%$, no mesmo sentido é a apelação cível $\mathrm{n}^{\circ}$ 0001131-65.2018.8.16.0193 que reconheceu a aplicabilidade da referida teoria no patamar de $87,5 \%$.

Ao comparar o percentual efetivamente aplicado pelo TJPR com o TJGO, há diferença de 4\% que, por meio de uma percepção menos detalhista, pode representar um percentual ínfimo, no entanto, no caso concreto pode representar uma diferença significativa e culminar em disparidade de decisões judiciais.

É importante ressaltar que tal disparidade pode aumentar, pois o TJPR (2019) negou provimento à apelação cível $\mathrm{n}^{\circ}$ 0049499-02.2014.8.16.0014, porquanto o desembargador relator entendeu que o adimplemento de $72 \%$ do contrato não configura a aplicação da teoria do adimplemento substancial, pois que, em seu entendimento, o percentual mínimo para aplicação da teoria é de $90 \%$. Por meio desse acórdão, é perceptível a tendência de se elevar o percentual mínimo aceito.

Por outro lado, o Tribunal de Justiça do Mato Grosso - TJMT, por intermédio das apelações cíveis $n^{\circ}$ 0035478-80.2011.8.11.0041 (2015) e 0006375-38.2013.8.11.0015 (2014), possuem o mesmo entendimento do TJGO.

Contudo, os Tribunais de Justiça dos Estados de São Paulo, Minas Gerais, Ceará, Pernambuco e Tocantins possuem entendimento de que a aplicação da teoria do adimplemento substancial é de, no mínimo, 70\%, divergindo, portanto, do TJGO.

\section{CONSIDERAÇões FINAIS}

É possível concluir que a teoria do adimplemento substancial não possui previsão legal no ordenamento jurídico brasileiro, sendo, portanto, uma criação doutrinária e jurisprudencial.

Para o Tribunal de Justiça do Estado de Goiás - TJGO, o termo "valor ínfimo", um dos três requisitos para aplicação da teoria do adimplemento substancial, corresponde ao adimplemento mínimo de $80 \%$ do contrato celebrado.

É importante ressaltar que a hipótese inicial de que o percentual mínimo era de $80 \%$ foi acertada, inclusive quanto ao instrumento utilizado para debater a teoria, qual seja, recurso de apelação.

Assim, é evidente que o percentual adotado pelo TJGO é alto, razão pela qual a aplicabilidade da teoria torna-se exceção em meio as demandas judiciais analisadas pelo tribunal.

Ao analisar a quantidade de acórdãos selecionados inicialmente para compor os resultados (371) e a quantidade final (247) é possível concluir, ainda, que o TJGO possui poucos julgados acerca da teoria, em média 123,6 acórdãos por ano.

Verifica-se que a teoria do adimplemento substancial ainda é vista com bastante receito pelo TJGO, motivo pela qual o número de aplicações nos casos concretos é baixo, pois das 247 jurisprudências apenas 26 casos foram compatíveis.

Ao analisar os acórdãos proferidos pelo TJGO, entre os anos de 2016 e 2019 que acolheram a teoria, o percentual médio é elevado para $86,62 \%$, enquanto o percentual médio 
aceito pelos principais tribunais das unidades federativas do Brasil é de 73,64\%. Assim, é possível concluir que há alta resistência, por parte do TJGO, em aplicar a teoria.

No entanto, no próprio TJGO, há precedentes minoritários que admitem a aplicação da referida teoria em contratos adimplidos a partir de $68,75 \%$, desde que não sejam oriundos do Decreto-Lei 911/69, em virtude do critério de especialidade das normas, o que demonstra uma maior flexibilidade da teoria por uma pequena minoria de julgadores que podem influenciar uma possível flexibilização da teoria diante do atual cenário de pandemia da Covid-19.

Na perspectiva comparatista, é perceptível a discrepância no percentual aceito entre os principais tribunais da unidade federativa, variando o percentual aceito de $70 \%$ a $84 \%$, o que representa uma variação de $14 \%$ entre um tribunal e outro, o que corrobora para uma instabilidade jurídica e ocorrência de decisões discrepantes em casos semelhantes, de modo que, ao celebrar um contrato de grande vulto e a depender da condição econômica da parte, é recomendável criar uma cláusula de foro para os tribunais que aceitam o menor índice.

Ainda, na lista de ranking, o TJGO exige o segundo maior percentual referente ao "valor ínfimo" para aplicar a teoria do adimplemento substancial, perdendo apenas para o TJPR. Nesse viés, é conclusivo que o termo "valor ínfimo" possui interpretações diferentes em cada tribunal da unidade federativa analisados neste artigo.

Como consequência da discrepância dos percentuais aceitos por cada tribunal, é confirmada a hipótese inicial de que poderá ocorrer disparidade entre as decisões judiciais proferidas por cada tribunal se comparado o percentual aplicado de acordo com o caso concreto.

Nesse sentido, é necessário, por parte do TJGO, uma revisão no entendimento do percentual mínimo para aplicabilidade da teoria do adimplemento substancial face ao atual cenário socioeconômico ocasionado pela pandemia da Covid-19.

A revisão no atual entendimento, com a consequente redução no percentual mínimo de adimplemento de $80 \%$ para $70 \%$ poderá representar grande avanço em território goiano, pois se equipararia ao entendimento da maioria dos tribunais e, naturalmente, iria gerar justiça socioeconômica no cenário pós cóvid-19.

Por fim, sugere-se ao STJ que discuta a presente teoria com o escopo de estabelecer um percentual mínimo para o requisito "valor ínfimo", haja vista que tal discussão poderá evitar o protocolo de recursos especiais e irá resultar em maior segurança jurídica para quem precisa de recorrer ao poder judiciário.

\section{REFERÊNCIAS}

ARAÚJO, T. C. D. Apontamentos sobre a teoria do adimplemento substancial. Migalhas, janeiro 2017. Disponivel em: <https://www.migalhas.com.br/depeso/252440/apontamentos-sobre-a-teoria-do-adimplemento-substancial>. Acesso em: 29 jun. 2020.

BECKER, A. A doutrina do adimplemento substancial no Direito brasileiro e em perspectiva comparativista. Revista da Faculdade de Direito da Universidade Federal do Rio Grande do Sul, Rio Grande do Sul, v. 09, n. 01, p. 60-77, 1993. 
BRASIL. Decreto-Lei n 911/69, de 01 de outubro de 1969. Disponível em: <http://www. planalto.gov.br/ccivil_03/decreto-lei/1965-1988/del0911.htm>. Acesso em: 18 jun. 2020.

. Lei 10.406, de 10 de janeiro de 2002 (institui o Código Civil). Disponível em: $<$ http://www.planalto.gov.br/ccivil_03/leis/2002/110406.htm>. Acesso em: 18 jun. 2020.

. Lei n $\mathbf{1 3 . 8 7 4}$, de 20 de setembro de 2019. Institui a declaração dos direitos econômicos. Disponível em: <http:/www.planalto.gov.br/ccivil_03/_Ato2019-2022/2019/Lei/ L13874.htm>. Acesso em: 03 jul. 2020.

. Medida Provisória 881, de 30 de abril de 2019. Institui a declaração de direitos da liberdade econômica. Disponível em: <http://www.planalto.gov.br/ccivil_03/_Ato20192022/2019/Mpv/mpv881.htm>. Acesso em: 03 jul. 2020.

BUSSATTA, E. L. Resolução dos Contratos e Teoria do Adimplemento Substancial. 2. ed. São Paulo: Saraiva, 2008.

CHAVES, C.; ROSENVALD, N. Curso de direito civil: contratos. 6. ed. Salvador: JusPodivm, p. 200, 2016.

CONSELHO DA JUSTIÇA FEDERAL. IV Jornada de Direito Civil: Enunciado 361. CJF - Enunciados, 2006. Disponivel em: <https://www.cjf.jus.br/enunciados/enunciado/472>. Acesso em: 15 jun. 2020.

COUTO E SILVA, C. A obrigação como processo. Rio de Janeiro: FGV, 2006.

JUNIOR, O. L. R.; RODAS, S. Entrevista com Reinhard Zimmermann e Jan Peter Schimidt. Revista de Direito Civil Contemporâneo, v. 5, ano 2, out-dez., 2015, p. 355. Disponível em: <http://ojs.direitocivilcontemporaneo.com/index.php/rdcc/article/view/79>. Acesso em 30 nov. 2021.

MOURA, L. L. D. Análise comparativa da aplicabilidade da teoria do adimplemento substancial em contratos garantidos por alienação fiduciária e reserva de domínio. Estudos Aplicados de Direito Empresarial, São Paulo, 2020.

PAULA, M. J. A Teoria do adimplemento substancial da obrigação no Brasil. Revista Eletrônica do Direito Privado da UEL, Londrina, v. 3, n. 2, maio/ago 2010, p. 43-67. Disponível em: <https:/www.uel.br/revistas/direitoprivado/artigos/43-67_Marcos_Jos\%C3\%A9_Paula_Teoria_adimplemento.pdf>. Acesso em 30 nov. 2021.

PINTO, C. S. Aplicabilidade da Teoria do Adimplemento Substancial a. C. (antes do covid) e d. C. (depois do covid). Migalhas, 07 maio 2020. Disponivel em: <https://www. migalhas.com.br/coluna/migalhas-contratuais/326239/aplicabilidade-da-teoria-do-adimplemento-substancial-a-c-antes-do-covid-e-d-c-depois-do-covid>. Acesso em: 30 nov. 2021. 
STJ. Recurso Especial: REsp 1.622.555/MG. Relator: Marcos Buzzi. DJ: 16/03/2017. Disponível em: <https://scon.stj.jus.br/SCON/>. Acesso em: 02 jul. 2020.

. Recurso Especial: REsp 76.362/MT. Relator: Ruy Rosado de Aguiar. DJ: 11/12/1995. Disponível em: < https://arquivocidadao.stj.jus.br/index.php/recurso-especial-n-76-362-mt >. Acesso em: 30 nov. 2021.

TARTUCE, F. Direito Civil: Teoria Geral dos Contratos e Contratos em Espécie. 14 ed., v. 03. Rio de Janeiro: Forense, 2019.

TJAM. Apelação Cível: APC 0612536-13.2017.8.04.0001. Relatora: Maria do Perpétuo Socorro Guedes Moura. DJ: 15/10/2018. JusBrasil, 2020. Disponível em: <https://tj-am.jusbrasil.com.br/jurisprudencia/645840964/apelacao-apl-6284133220138040001-am-0628413-3220138040001/inteiro-teor-645840990>. Acesso em: 02 jul. 2020.

TJBA. Agravo de Instrumento: AI 0014962-57.2016.8.05.0000. Relator: Mauricio Kertzman. DJ: 28/11/2016. Disponível em: <https://jurisprudencia.tjba.jus.br/>. Acesso em: 02 jul. 2020.

Apelação Cível: APC 0016992-31.2017.8.05.0000. Relatora: Pilar Celia Tobio de Claro. DJ: 06.02.2018. Disponível em: $<$ https://jurisprudencia.tjba.jus.br/>. Acesso em: 02 jul. 2020.

TJCE. Agravo Regimental: AGR 0000896-34.2006.8.06.0117/50000. Relator: Antônio Pádua Silva. JusBrasil, 2020. Disponível em: $<$ hhttps://tj ce.jusbrasil.com.br/jurisprudencia/321776671/agravo-agv-8963420068060117-ce-0000896-3420068060117?ref=amp $>$. Acesso em: 02 jul. 2020.

TJDFT. Apelação Cível: APC 20151410081782. Relator: Carlos Rodrigues. DJ: 01/02/2017. Disponível em: <https://pesquisajuris.tjdft.jus.br/IndexadorAcordaos-web/sistj>. Acesso em: 02 jul. 2020.

Agravo de Instrumento: AI 20140020252795. Relator: Alfeu Machado. DJ: 12/11/2014. Disponível em: <https://pesquisajuris.tjdft.jus.br/IndexadorAcordaos-web/ sistj>. Acesso em: 02 jul. 2020.

TJGO. Apelação Cível: 0143931-48.2001.8.09.0051. Relator: Mauricio Porfirio Rosa. DJ: 18/07/2019. Disponível em: <https:/www.tjgo.jus.br/jurisprudencia/juris.php>. Acesso em: 02 jul. 2020.

. Apelação Cível: APC 0154806-73.2016.8.09.0044. Relator: Sebastião Luiz Fleury. DJ: 30/08/2019. Disponível em: <https://www.tjgo.jus.br/jurisprudencia/juris.php>. Acesso em: 02 jul. 2020.

Apelação Cível: APC 0112952-30.2006.8.09.0051. Relator: Itamar de Lima. DJ: 
26/07/2019. Disponível em: <https:/www.tjgo.jus.br/jurisprudencia/juris.php>. Acesso em: 02 jul. 2020.

. Apelação Cível: APC 0056940-49.2013.8.09.0051. Relator: Carlos Alberto França. DJ: 18/05/2018. Disponível em: <https:/www.tjgo.jus.br/jurisprudencia/juris.php>. Acesso em: 02 jul. 2020.

. Apelação Cível: APC 0060594-42.2015.8.09.0029. Relator: Maria das Graças Carneiro Requi. DJ: 29/02/2019. Disponível em: <https://www.tjgo.jus.br/jurisprudencia/juris. php>. Acesso em: 02 jul. 2020.

Apelação Cível: APC0218151-58.2016.8.09.0029. Relator: Sérgio Mendonça de Araújo. DJ: 23/08/2019. Disponível em: <https://www.tjgo.jus.br/jurisprudencia/juris. php>. Acesso em: 02 jul. 2020.

. Habeas Corpus: HC 5158182-12.2019.8.09.0000. Relator: Nincomedes Domingos Borges. DJ: 09/07/2019. Disponível em: <https://www.tjgo.jus.br/jurisprudencia/juris. php>. Acesso em: 02 jul. 2020.

. Apelação Cível: APC 0328342-46.2012.8.09.0051. Relator: Sebastião Luiz Fleury. DJ: 10/05/2019. Disponível em: <https://www.tjgo.jus.br/jurisprudencia/juris.php>. Acesso em: 02 jul. 2020.

. Apelação Cível: APC 0411710-09.2013.8.09.0021. Relator: Leobino Valente Chaves. DJ: 13/06/2019. Disponível em: <https://www.tjgo.jus.br/jurisprudencia/juris.php>. Acesso em: 02 jul. 2020.

. Agravo de Instrumento: AI 160555-09.2016.8.09.0000. Relator: Francisco Vildon José Valente. DJ: 03/10/2016. Disponível em: <https://www.tjgo.jus.br/jurisprudencia/juris.php>. Acesso em: 02 jul. 2020.

Apelação Cível: APC 0257042-53.2014.8.09.0051. Relator: Roberto Horácio de Rezende. DJ: 31/07/2018. Disponível em: <https://www.tjgo.jus.br/jurisprudencia/juris. php>. Acesso em: 02 jul. 2020.

. Agravo de Instrumento: AI 330855-38.2015.8.09.0000. Relator: Gerson Santana Cintra. DJ:04/04/2016. Disponível em: $<$ https://www.tjgo.jus.br/jurisprudencia/juris.php $>$. Acesso em: 02 jul. 2020.

. Apelação Cível: APC 0402885-09.2013.8.09.0011 . Relator: Zacarias Neves Coelho. DJ: 05/10/2017. Disponível em: <https://www.tjgo.jus.br/jurisprudencia/juris.php>. Acesso em: 02 jul. 2020.TJGO. Apelação Cível: 0143931-48.2001.8.09.0051. Relator: Mauricio Porfirio Rosa. DJ: 18/07/2019. Disponível em: <https://www.tjgo.jus.br/jurisprudencia/juris.php>. Acesso em: 02 jul. 2020.

. Apelação Cível: APC 0154806-73.2016.8.09.0044. Relator: Sebastião Luiz Fleury. 
DJ: 30/08/2019. Disponível em: <https://www.tjgo.jus.br/jurisprudencia/juris.php>. Acesso em: 02 jul. 2020.

. Apelação Cível: APC 0112952-30.2006.8.09.0051. Relator: Itamar de Lima. DJ: 26/07/2019. Disponível em: <https:/www.tjgo.jus.br/jurisprudencia/juris.php>. Acesso em: 02 jul. 2020.

. Apelação Cível: APC 0056940-49.2013.8.09.0051. Relator: Carlos Alberto França. DJ: 18/05/2018. Disponível em: <https:/www.tjgo.jus.br/jurisprudencia/juris.php>. Acesso em: 02 jul. 2020.

Apelação Cível: APC 0060594-42.2015.8.09.0029. Relator: Maria das Graças Carneiro Requi. DJ: 29/02/2019. Disponível em: <https://www.tjgo.jus.br/jurisprudencia/juris. php>. Acesso em: 02 jul. 2020.

Apelação Cível: APC0218151-58.2016.8.09.0029. Relator: Sérgio Mendonça de Araújo. DJ: 23/08/2019. Disponível em: <https://www.tjgo.jus.br/jurisprudencia/juris. php>. Acesso em: 02 jul. 2020.

. Habeas Corpus: HC 5158182-12.2019.8.09.0000. Relator: Nincomedes Domingos Borges. DJ: 09/07/2019. Disponível em: <https:/www.tjgo.jus.br/jurisprudencia/juris. php>. Acesso em: 02 jul. 2020.

. Apelação Cível: APC 0328342-46.2012.8.09.0051. Relator: Sebastião Luiz Fleury. DJ: 10/05/2019. Disponível em: <https://www.tjgo.jus.br/jurisprudencia/juris.php>. Acesso em: 02 jul. 2020.

. Apelação Cível: APC 0411710-09.2013.8.09.0021. Relator: Leobino Valente Chaves. DJ: 13/06/2019. Disponível em: <https://www.tjgo.jus.br/jurisprudencia/juris.php>. Acesso em: 02 jul. 2020.

Agravo de Instrumento: AI 160555-09.2016.8.09.0000. Relator: Francisco Vildon José Valente. DJ: 03/10/2016. Disponível em: <https://www.tjgo.jus.br/jurisprudencia/juris.php>. Acesso em: 02 jul. 2020.

Apelação Cível: APC 0257042-53.2014.8.09.0051. Relator: Roberto Horácio de Rezende. DJ: 31/07/2018. Disponível em: <https://www.tjgo.jus.br/jurisprudencia/juris. php>. Acesso em: 02 jul. 2020.

. Agravo de Instrumento: AI 330855-38.2015.8.09.0000. Relator: Gerson Santana Cintra. DJ:04/04/2016. Disponível em: < https://www.tjgo.jus.br/jurisprudencia/juris.php>. Acesso em: 02 jul. 2020.

Apelação Cível: APC 0402885-09.2013.8.09.0011 . Relator: Zacarias Neves Coelho. DJ: 05/10/2017. Disponível em: <https://www.tjgo.jus.br/jurisprudencia/juris.php>. Acesso em: 02 jul. 2020. 
TJMG. Apelação Cível: APC 0631973-92.2012.8.13.0024. Relator: Marco Aurelio Ferenzini. DJ: 12/08/2016. Disponível em: <https://www5.tjmg.jus.br/jurisprudencia/formEspelhoAcordao.do>. Acesso em: 02 jul. 2020.

TJMT. Apelação Cível: APC 0035478-80.2011.8.11.0041. Relatora: Serly Marcondes A1ves. DJ: 09/02/2015. JusBrasil, 2020. Disponível em: < https://tj-mt.jusbrasil.com.br/jurisprudencia/867513966/apelacao-apl-354788020118110041-mt?ref=feed $>$. Acesso em: 03 jul. 2020

. Apelação Cível: APC 0006375-38.2013.8.11.0015. Relator: Cleuci Terezinha Chagas. DJ: 05/05/2014. Radar Oficial, 2020. Disponível em: <http://www.radaroficial.com. br/d/4832037793955840 >. Acesso em: 05 jul. 2020.

. Apelação Cível: APC 0004904-09.2013.8.11.0040. Relatora: Cleuci Terezinha Chagas Pereira da Silva. DJ: 15/03/2017. JusBrasil, 2020. Disponível em: <https://tj-mt.jusbrasil.com.br/jurisprudencia/439321184/apelacao-apl-49040920138110040-157687-2016>. Acesso em: 03 jul. 2020.

TJPE. Apelação Cível: APC 0004850-75.2014.8.17.2001. Relator: Steno Jose de Sousa Neiva Coelho. DJ: 05/05/2017. Disponível em: < $\underline{\text { http://www.tjpe.jus.br/consultajurispru- }}$ denciaweb/xhtml/consulta/consulta.xhtml >. Acesso em: 03 jul. 2020.

TJPR. Apelação Cível: APC 0015099-25.2016.8.16.0035. Relatora: Joeci Machado Camargo. DJ: 18/06/2019. Disponível em: <http://portal.tjpr.jus.br/jurisprudencia/>. Acesso em 02 jul. 2020.

. Apelação Cível: APC 0001131-65.2018.8.16.0193. Relator: Mário Luiz Ramidoff. DJ: 17/09/2019. Disponível em: <http://portal.tjpr.jus.br/jurisprudencia/>. Acesso em: 02 jul. 2020.

Apelação Cível: APC 0049499-02.2014.8.16.0014. Relator: Vitor Roberto Silva. DJ: 30/09/2019. Disponível em: <http://portal.tjpr.jus.br/jurisprudencia/>. Acesso em: 02 jul. 2020.

TJSP. Apelação Cível: APC 0002322-45.2012.8.26.0075. Relator: Mônica de Carvalho. DJ: 29/03/2019. Disponível em: <https://esaj.tjsp.jus.br/cjsg/resultadoCompleta.do>. Acesso em: 02 jul. 2020.

. Agravo de Instrumento: AI 2220701-03.2019.8.26.0000. Relator: Roberto Mac Cracken. DJ: 26/03/2020. Disponível em: <https://esaj.tjsp.jus.br/cjsg/resultadoCompleta. do>. Acesso em: 02 jul. 2020.

TJTO. Apelação Cível: APC 0004666-27.2017.827.0000. Relatora: Celia Regina Reis. DJ: 28/06/2017. Disponível em: <http://jurisprudencia.tjto.jus.br/consulta?q=0004666-27.2017.827.0000>. Acesso em: 02 jul. 2020. 
. Apelação Cível: APC 0014800-16.2017.827.0000. Relator: Ronaldo Eurípedes de Souza. DJ: 11/03/2019. Disponível em: <http://jurisprudencia.tjto.jus.br/consulta?q=0014800-16.2017.827.0000> Acesso em: 02 jul. 2020.

VENOSA, S.; DENSA, R. Mora em tempos de pandemia. Migalhas, 14 abr. 2020. Disponivel em: <https:/www.migalhas.com.br/depeso/324596/mora-em-tempos-de-pandemia $>$. Acesso em: 30 nov. 2021.

\section{DAdos Do AUTOR}

\section{Felipe Aquino Domiciano}

Mestrando em Direitos Humanos pela Universidade Federal de Goiás - UFG. E-mail: felipeaquino@discente.ufg.br 